\title{
Effect of long duration rainstorm on stability of Red-clay slopes
}

\author{
Kaixi Xue ${ }^{1}$, Beena Ajmera ${ }^{2 *}$, Binod Tiwari ${ }^{3}$ and Yanxiang $\mathrm{Hu}^{1}$
}

\begin{abstract}
Background: Slope stability issue in red clay slopes during rainfall is one among the serious geoenvironmental disasters in China. In order to investigate the effect of long duration rainstorm on red-clay slopes, studies were conducted using Geostudio 2012. Five different rainfall-durations were applied to the slope and the results of coupled and uncoupled calculation modes were compared.

Results and Conclusions: Results show that pore water pressure increased due to the dissipation of matric suctions and rise in water table during the rainfall period with the longer the rainfall duration, the larger the pore water pressure. The rate of change of pore water pressure was largest at rainfall durations of 4 days, among all the duration conditions considered for this study. After short duration rainstorms, a settlement of the surface of the slope was observed. However, in long duration rainstorms, the slope surface swelled in a non-uniform manner with the head of the slope experiencing the greatest expansion. Factor of safety exhibited a hysteresis during the calculation process, which was similar in trend with the pore water pressure as well, and it showed some amplitude during the calculation steps under the coupled calculation analysis as a result of the deformation and seepage force affecting each other on the performance of slope, especially for the slope stability.
\end{abstract}

Keywords: Unsaturated soil, Red-clay, Rainfall infiltration, Slope stability, Water table

\section{Background}

With global warming, the world has been experiencing more extreme rainfall events in recent years compared to the past. The south region of Changjiang River in China that has hot and humid climatic conditions is not an exception. These regions are susceptible to rainfallinduced slope failure issues, which is one among the major geo-disasters in China. As rainfall is one of the key factors triggering slope failures, amount of landslides increased with an increase in extreme-rainfall events. Past experiences show that slope failures generally occur during or after the rainfall event; for an example at about 6:40 pm local time on 24 June 2015, a huge landslide occurred on the north bank of Daning River in Chongqing city, China after a heavy rainfall for a few days. The landslide involved about 2000 cubic meters of sediments collapsing into the river, triggering a series of waves up to six meters high, which overturned a total of

\footnotetext{
* Correspondence: bajmera@fullerton.edu

${ }^{2}$ Civil \& Environmental Engineering Department, California State University, 800 N State College Blvd, E-318, 92831 Fullerton, CA, USA

Full list of author information is available at the end of the article
}

thirteen vessels on the river, mostly small fishing boats and one $14 \mathrm{~m}$ long patrol boat. One person was dead following the incident and four others were injured.

Majority of the landslides are triggered by soil-water interaction, when flooding or high rainfall cause unsaturated sediments to lose their apparent cohesion, triggering collapses. One of the earliest academic researches about the relationship between rainfall and landslides dates back to 1961 when Lumb (1962) reported that erosion by water during the rainy season is responsible for active sliding in high rainfall areas. By now, how the characteristics of rainfall, namely, rainfall intensity and duration, antecedent rainfall, and rainfall patterns affects the slope stability are well researched topics and many prominent theories about the slope failure mechanism have been published in literature.

Keefer et al. (1987) collected historical data from the San Francisco Bay region, California, followed by qualitative analysis to develop a relationship between rainfall and landslides in order to create a real-time early warnings system for the storms of 12 to 21 February 1986. This system successfully predicted the times of major landslide events. Since then, several quantitative methods were developed 
involving many parametric studies using the finite element analysis method. It was found that the slope stability not only depends on the intensity of rainfall and the initial groundwater table, but also on rainfall duration $(\mathrm{Ng}$ and Shi 1998; Song et al. 2002; Wang and Liang 2010). Liu et al. (2012) conducted a numerical simulation to show that the hydro-mechanical coupling process works during rainfall. The results indicated that greater the rainfall intensity is, the larger the difference between the coupling and uncoupling condition is for the factor of safety of the slope.

Another current research focus area is the effect of rainfall patterns on slope stability. A physical model has been used to investigate the importance of the rainfall pattern for shallow landslide (Brooks and Richards 1994; Dhakal and Sidle 2004). Their results showed that different storm types are associated with different rainfall patterns, which then take a different effect on the timing and depth of slope instability. Tsai (2008) noted the above mentioned studies were based on saturated soils, but soil failure could also be induced by a decrease in unsaturated shear strength owing to the dissipation of matric suction. Therefore, further experiments were conducted using physical shallow landslide models taking into account the shear strength of unsaturated soil for the infinite slope stability analysis. The experimental results show that for each rainfall pattern, the failure depths and the times of failure from the same amount of rainfall with different durations could be largely different (Tsai and Wang 2011).

Antecedent rainfall is the other importance characteristic which can affect the stability of slopes. Numerical modeling results for the slope failures were presented by Rahardjo et al. (2001) for slopes in Singapore. The results demonstrate that antecedent rainfall does play an important role in slope stability. Rahimi et al. (2010) conducted a transient seepage analysis on soil slopes applying three different antecedent rainfall patterns and their results indicated that antecedent rainfall affected the stability of both high-conductivity (HC) and lowconductivity (LC) soil slopes. However, the stability of the LC soil slope was more significantly affected than the HC soil slope. Mukhlisin and Taha (2012) developed a numerical model to estimate the effect of antecedent rainfall on an unsaturated slope. Results showed that under a rainstorm event, slope failure occurred at a comparably similar time although the antecedent rainfall drainage periods prior to the major rainfall were different (i.e., $24 \mathrm{~h}, 48 \mathrm{~h}$ and $96 \mathrm{~h}$ ). However, under weak rainfall conditions, the differences of the antecedent rainfall drainage periods have a significant effect on development of pore-water pressure. Tiwari and Upadhyaya (2014) investigated a landslide area located in Kathmandu, Nepal to show that the collapse was a result of the effect of antecedent rainfall and unplanned construction activities.
From research results presented above, the overwhelming development in the research field of slope stability during rainfall can be seen. However, to provide valid and applicable theories which can be used to evaluate or predict slope stability under rainfall conditions, more work is needed. Although some of the previous studies have made the correlations between the rainfall properties and the slope stability, they have not considered extreme-rainfall conditions, i.e., heavy-rain for very long duration, drying for a very long duration and following long duration wetting and drying cycles. Moreover, most of the studies mentioned above are about rainfall infiltration into the soil slope only considering the transient seepage focus on the change of porewater pressure. However, less information is provided for the change in deformation coupled with the seepage force. Hence, the study presented in this paper focuses on the effect of extreme-rainfall duration on the stability of red-clay slope in Jiangxi Province, China. Very long durations of uniform heavy rainfall were applied to slopes in order to show the changes of the characteristics of the slope. Analysis of coupled (seepage and deformation) and uncoupled (seepage only) analysis are conducted to compute the pore-water pressures. The results were, then, used to calculate the factor of safety during extreme-rainfall. The difference in the results of two calculation modes are compared.

\section{Theoretical consideration}

\section{Uncoupled analysis (seepage only)}

The uncoupled analysis was conducted using SEEP/W. More specifically, SEEP/W program deals with the fundamental flow laws for steady state and transient flow based on Darcy's law (GEO-SLOPE International, Ltd 2014a). Darcy's law was originally derived for saturated soil, but later research has shown that it can also be applied to the flow of water through unsaturated soil (Brooks and Richards 1994). The water-flow governing differential equation, which was derived for solving transient and two-dimensional seepage analysis, can be expressed as:

$$
\frac{\partial}{\partial \mathrm{x}}\left(k_{x} \frac{\partial H}{\partial x}\right)+\frac{\partial}{\partial \mathrm{y}}\left(k_{y} \frac{\partial H}{\partial y}\right)+Q=m_{w} \gamma_{w} \frac{\partial H}{\partial t}
$$

Where $\mathrm{H}=$ the total head; $\mathrm{k}_{\mathrm{x}}$ and $\mathrm{k}_{\mathrm{y}}=$ the hydraulic conductivity in the $\mathrm{x}$ - and $\mathrm{y}$-directions, respectively; $\mathrm{Q}=$ the applied boundary flux; $\gamma_{\mathrm{w}}=$ the unit weight of water; $\mathrm{m}_{\mathrm{w}}=$ the slope of the storage curve; $\mathrm{y}=$ the elevation; and $\mathrm{t}=$ time. Equation 1 assumes that constant total stress conditions are maintained during the analysis. It is also formulated on the assumption that the pore-air pressure remains constant and is equal to the atmospheric pressure during the transient processes. 


\section{Coupled analysis (concurrent seepage and deformation)} The coupled analysis was conducted using SIGMA/W (Geostudio 2012). SIGMA/W is formulated to solve soil consolidation problems using a fully coupled or any of several un-coupled options. A fully coupled analysis requires that both the stress-deformation and seepage dissipation equations be solved simultaneously (GEO-SLOPE International, Ltd 2013). With the coupled analysis, it is no longer necessary to have both SEEP/W and SIGMA/ W. All hydraulic properties and boundary conditions can be developed and applied from within SIGMA/W.

In a coupled consolidation analysis, both equilibrium and flow equations are solved simultaneously. The finite element equilibrium equations are formulated using the principle of virtual work, which states that for a system in equilibrium, the total internal virtual work is equal to the external virtual work. The virtual work equation can be written as follows (Fredlund and Rahardjo 1993):

$$
\begin{aligned}
& \sum[B]^{T}[D][B]\{\Delta \delta\}+\sum[B]^{T}[D]\left\{m_{h}\right\}\langle N\rangle\left\{\Delta u_{W}\right\}=\sum F, \\
& {[K]=[B]^{T}[D][B],} \\
& {\left[L_{d}\right]=[B]^{T}[D]\left\{m_{h}\right\} N, \text { and }} \\
& \left\{m_{H}\right\}^{T}=\left\langle\frac{1}{H} \frac{1}{H} \frac{1}{H} 0\right\rangle .
\end{aligned}
$$

Where $[\mathrm{B}]=$ gradient matrix, (also called the strain matrix); $[D]=$ drained constitutive matrix; $[K]=$ stiffness matrix; $\left[\mathrm{L}_{\mathrm{d}}\right]=$ coupling matrix; $\{\Delta \delta\}=$ incremental displacement vector; and $\left\{\Delta \mathrm{u}_{\mathrm{w}}\right\}=$ incremental pore-water pressure vector.

\section{Slope stability (factor of safety)}

After pore-water pressure was obtained by SEEP/W and SIGMA/W, slope stability analysis was performed in this study by using SLOPE/W (GEO-SLOPE International, Ltd $2014 b)$. In the calculation process, general limit equilibrium methods were used, and a modified form of the Mohr-Coulomb equation was used to describe the shear strength of an unsaturated soil (i.e., a soil with negative pore-water pressures). The shear strength equation is:

$$
S_{m}=\frac{\beta}{F}\left(c^{\prime}+\left(\sigma_{n}-u_{a}\right) \tan \varnothing^{\prime}+\left(u_{a}-u_{w}\right) \tan \varnothing^{b}\right)
$$

Where $S_{m}=$ the shear force mobilized on the base of each slice; $\beta=$ the base length of each slice; $F=$ the factor of safety; $c^{\prime}=$ effective cohesion; $\sigma_{n}=$ total normal stress; $u_{\alpha}=$ pore-air pressure; $\varnothing^{\prime}=$ effective angle of internal friction; $u_{w}=$ pore-water pressure; $\varnothing^{b}=$ an angle defining the increase in shear strength for an increase in suction.

The above equation can be used for both saturated and unsaturated soils. For most analyses, the pore-air pressure can be set to zero. SLOPE/W uses $\varnothing^{b}$ whenever the pore-water pressure is negative and $\varnothing^{\prime}$ whenever the pore-water pressure is positive. Simplified Bishop's Method modified for the unsaturated condition has been used in this study.

\section{Methods}

\section{Slope geometry and boundary conditions}

The boundary size and conditions of the slope geometry will affect the accuracy of the calculation in numerical simulations. Zhang et al. (2003) conducted numerical

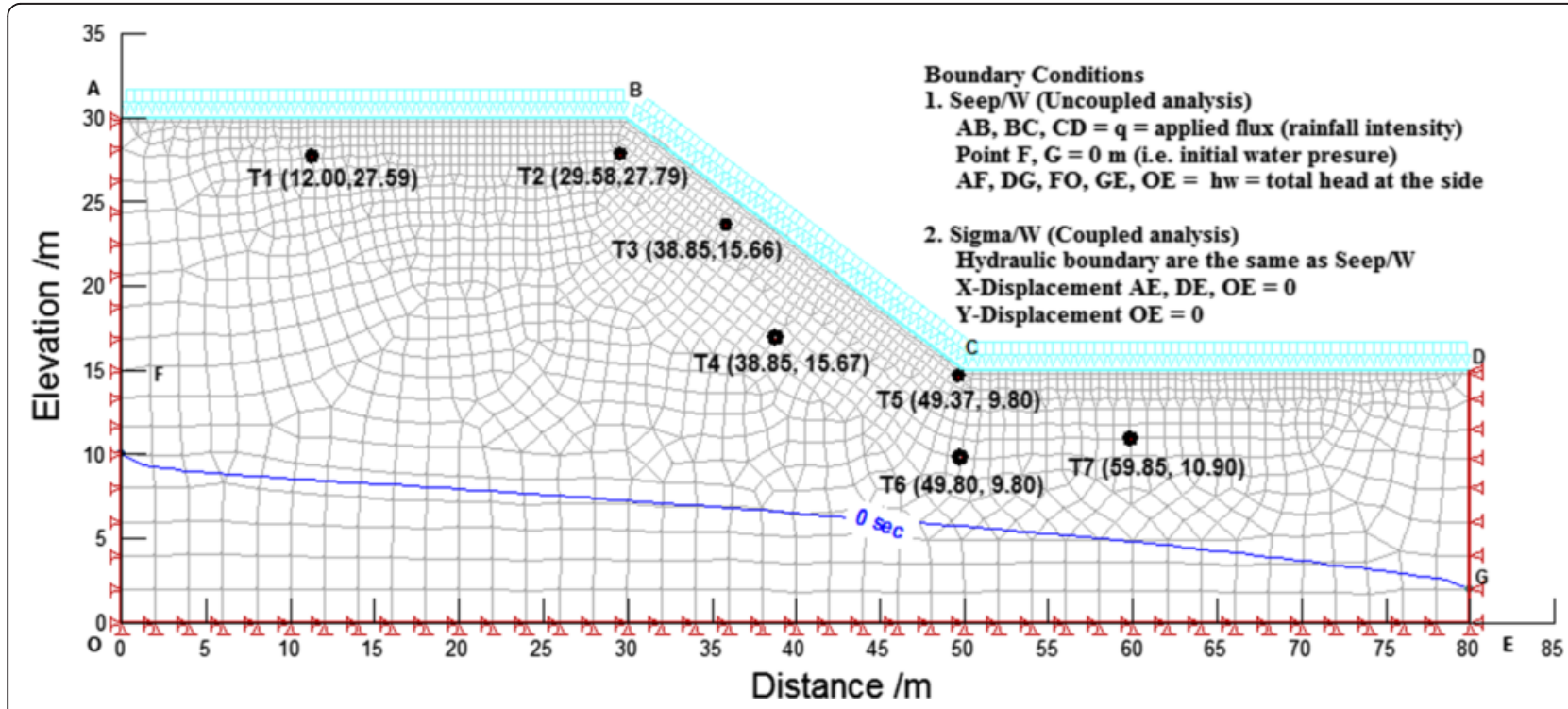

Fig. 1 Grain size distribution of the soil sample used in this study 
simulations in four groups with 106 numerical tests, and compared the results obtained. The best boundary size based on the study results was presented as follows: the distance from slope toe to left edge is 1.5 times height of the slope, the distance from slope crest to right edge is 2.5 times height of the slope, and the distance of bottom edge to slope crest should be more than twice the height of the slope. Slope geometry in this study was constructed according to the above suggestions, as presented in Fig. 1. In the constructed slope, the height of the slope, $\mathrm{h}_{\mathrm{w}}=15 \mathrm{~m}$, is typical in Jiangxi Province, China. The initial depth of the water table, $\mathrm{H}_{\mathrm{w}}$, was selected to be at the location presented in the Fig. 1, which is below the ground surface, which is the typical ground water condition in Jiangxi Province, China.

As presented in the model (Fig. 1), there are 2039 nodes, 2004 elements, and the elements near the top border of the slope are two times finer than the elements near the bottom. Boundary conditions include both hydraulic boundary and deformation boundary conditions, all of which have been shown in Fig. 1. Seven points were marked in Fig. 1 with numbers and coordinates, which were used to monitor the change of mechanical parameters, e.g., pore-water pressure, water head, stress, strain, and displacement.

\section{Soil properties}

Properties of the red clay samples obtained from the study area are presented in Table 1. These properties were obtained from appropriate laboratory tests as well as field measurements as mentioned in Table 1. Grain size distribution curve of the tested red clay sample is
Table 1 Geotechnical properties of red clay soil sample used in the numerical analysis

\begin{tabular}{lll}
\hline Material properties & Values & Measurement method \\
\hline Percentage of Sand & $77 \%$ & Sieve Analysis \\
Percentage of Fines & $23 \%$ & Sieve Analysis \\
$\begin{array}{l}\text { Type of Soil } \\
\text { Saturated Volumetric } \\
\text { Moisture Content, } \theta_{w}\end{array}$ & 0.37 & ASTM \\
$\begin{array}{l}\text { Saturated coefficient of } \\
\text { permeability, } \mathrm{k}_{\mathrm{s}}\end{array}$ & $0.0323 \mathrm{~m} / \mathrm{h}$ & Falling head permeability test \\
$\begin{array}{l}\text { Residual Moisture Content, } \\
\theta_{\mathrm{r}}\end{array}$ & 0.016 & $\begin{array}{l}\text { Estimated with Fredlund and } \\
\text { Unit Weight }\end{array}$ \\
$\mathrm{c}^{\prime}$ & $20 \mathrm{kN} / \mathrm{m}^{3}$ & $\begin{array}{l}\text { Field measurement } \\
\varphi^{\prime}\end{array}$ \\
\hline
\end{tabular}

presented in Fig. 2. The soil sample is classified as SM (silty sand) material. Sample functions method was used to estimate the volumetric water content function, as presented in Fig. 3. Saturated coefficient of permeability of the red-clay, $k_{s}$, was $0.0323 \mathrm{~m} / \mathrm{h}$, and the residual water content, $\theta_{n}$ was 0.016 . Fredlund and Xing's (1994) method was used to estimate the hydraulic conductivity function, as presented Fig. 4. Properties mentioned in Table 1 were used in the SLOPE/W coupled with SEEP/W analysis. In the SLOPE/W coupled with SIGMA/W (deformation coupled with seepage) analysis, an elasto-plastic material model was selected, with an effective modulus of elasticity, $\mathrm{E}^{\prime}=8.3 \mathrm{MPa}$, and Poisson's ratio, $\lambda=$ 0.334 . The other properties were the same as the uncoupled analysis. Although the soil properties,

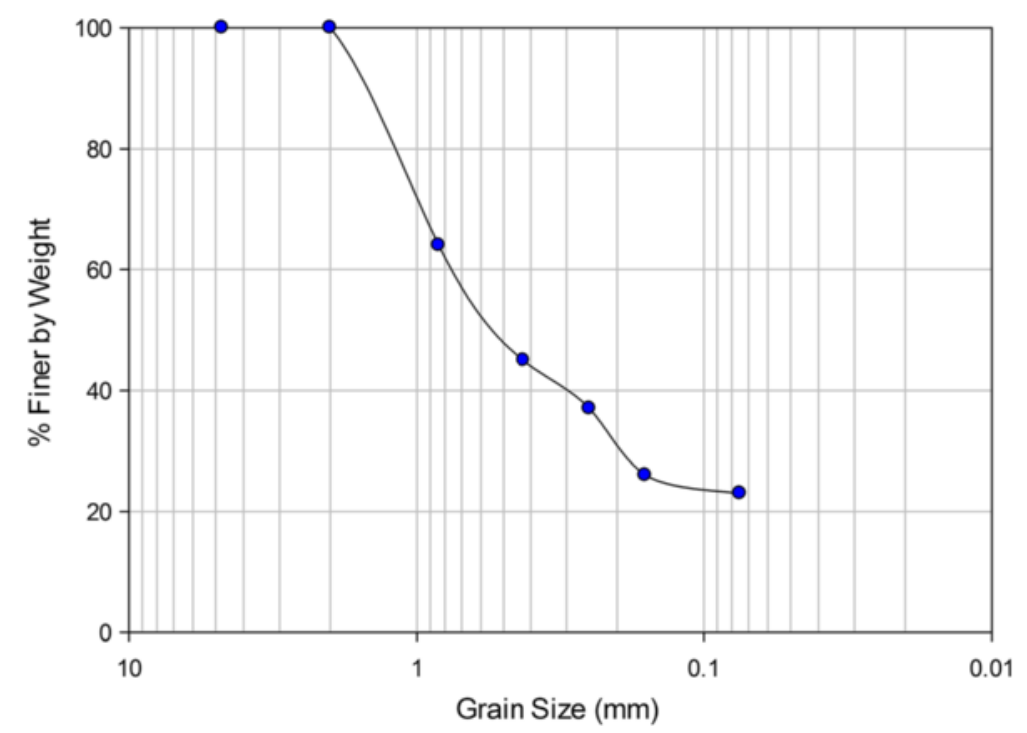

Fig. 2 Geometry, boundary conditions, and monitoring points marked in the typical soil slope in Jiangxi Province, China 


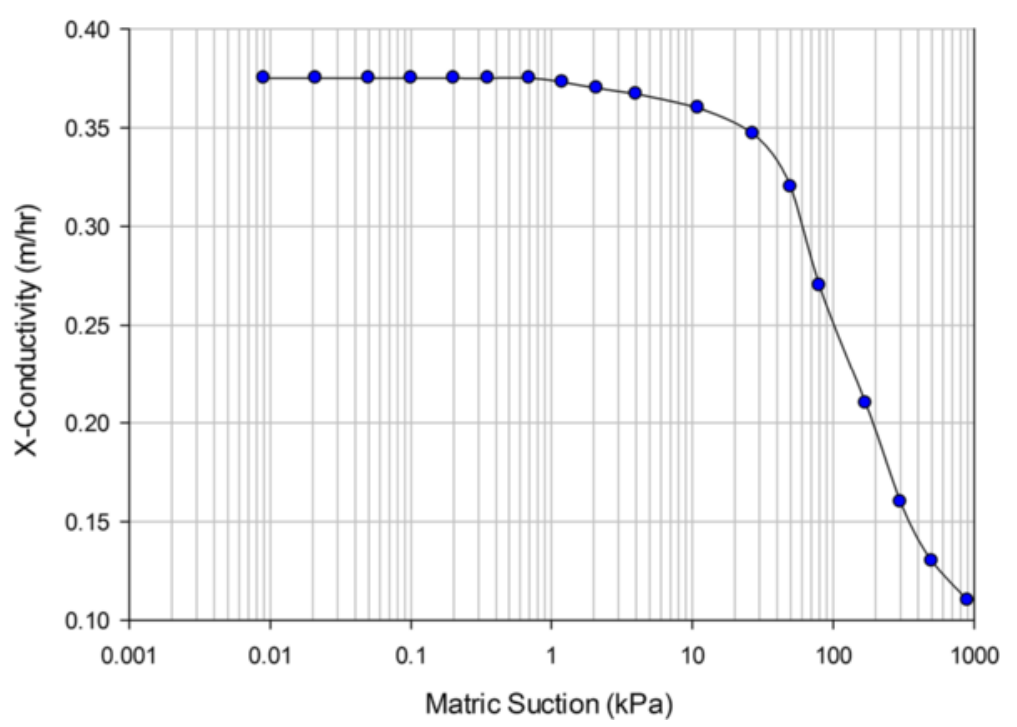

Fig. 3 Volumetric Water Content Function

including hydraulic conductivity, in the field is not homogeneous in the field, the soil has been considered as homogeneous in this study for simplicity.

\section{Studies on extreme-rainfall intensity and duration pattern} Table 2 shows the categories for the rainfall intensity in China. However, it is difficult to define the exact class as the extreme condition for triggering landslides. Only a few articles in the literature presented the concept qualitatively. (Xue et al. 2012) investigated 1695 geological disasters in Chongqing City, China. The relationship between rainfall intensity and the probability of slope failure was analyzed and a discriminant model of extreme-rainfall for inducing slope failure was derived. Results of the research suggested that the extreme-rainfall intensity is $168.69 \mathrm{~mm}$ per day. Historical records show that, in the rainy season (June to October), the average duration of rainstorm is 2 to 5 days in Jiangxi Province, China.

According to the discussion presented above, five rainfall-durations were selected, i.e., 1 day, 2 days, 3 days, 4 days, and 5 days. Uniform rainfall pattern was applied to the model with the rainfall intensity, $\mathrm{I}_{\mathrm{r}}$ of $6.25 \mathrm{e}-3 \mathrm{~m} /$ $h$. In general, there is a very small possibility for the rainfall duration exceeding 3 days. In this study, rainfall longer than 3 days period is termed as the very long duration rainfall event.

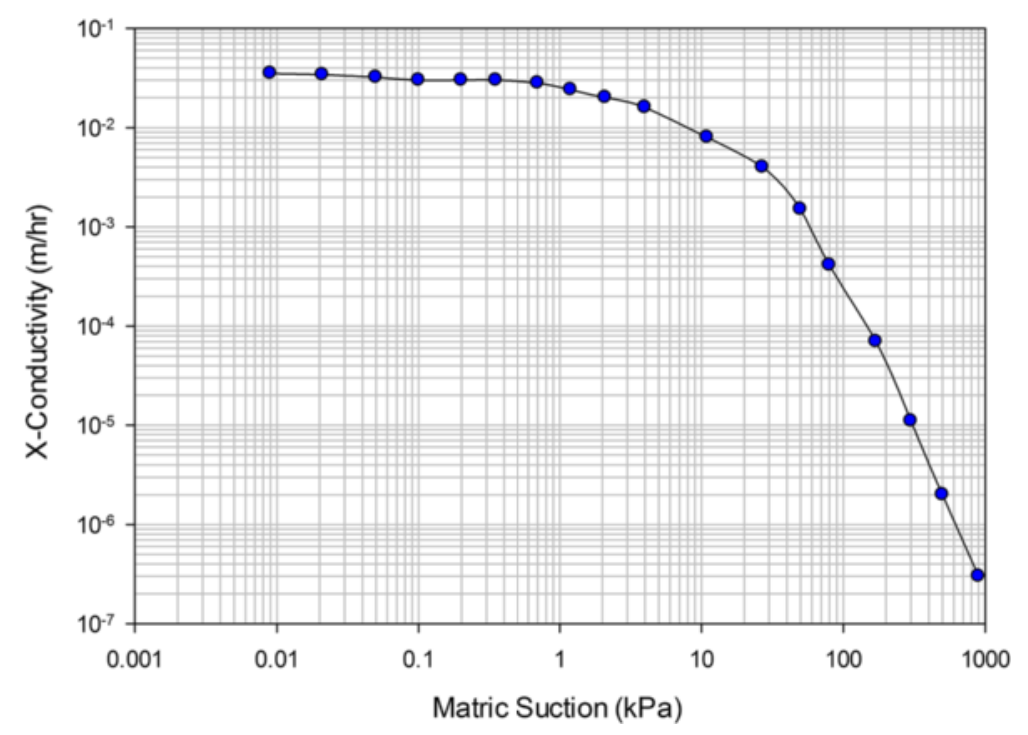

Fig. 4 SWCC and unsaturated permeability function 
Table 2 Classification criterion of rainfall intensity in China

\begin{tabular}{|c|c|c|c|c|c|c|c|}
\hline \multirow[t]{2}{*}{ Classification } & & \multirow[t]{2}{*}{ Weak-rain } & \multirow[t]{2}{*}{ Middle-rain } & \multirow[t]{2}{*}{ Heavy-rain } & \multicolumn{3}{|c|}{ Rainstorm } \\
\hline & & & & & 1 & $\|$ & III \\
\hline \multicolumn{2}{|c|}{ Value based on 24 h (mm) } & $<10$ & $<25$ & $<50$ & $<100$ & $<200$ & $>200$ \\
\hline \multicolumn{2}{|c|}{ Value based on 12 h (mm) } & $<5$ & $<10$ & $<30$ & $<70$ & $<140$ & $>140$ \\
\hline Uniform pattern $(\mathrm{m} / \mathrm{h})$ & 24 h style & $<4.2 \mathrm{E}-04$ & $<1.0 \mathrm{E}-03$ & $<2.1 \mathrm{E}-03$ & $<4.2 \mathrm{E}-03$ & $<8.3 \mathrm{E}-03$ & $>8.3 \mathrm{E}-03$ \\
\hline Uniform pattern (m/h) & 12 h style & $<2.1 \mathrm{E}-04$ & $<4.2 \mathrm{E}-04$ & $<1.3 \mathrm{E}-03$ & $<2.9 \mathrm{E}-03$ & $<5.8 \mathrm{E}-03$ & $>5.8 \mathrm{E}-03$ \\
\hline
\end{tabular}

\section{Results and discussion}

In this study, results of slope conditions were calculated for 240 different steps under each rainfall condition. Results from each step were utilized to evaluate the change in pore-water pressure, stress, strain, displacement, deformation and water table of the slope with rainfall.

\section{Dynamic change rule of seepage and pore-water pressures}

During the rainfall infiltration process, volumetric water content changed as rain-water infiltrated into the slope. The water table rose, and thus, the pore-water pressures distribution changed with time. Figures 5 and 6 show the locations of water table during the 5 days duration under rainstorm. The location of the water table exhibited a remarkable rise in level and rose to the highest position after 5 days of rainfall. Although the location of the water table presents the tendency of lowering following the prolonged calculation period, the final location is significantly higher than before. Hence, the uplift force applied from the underground water to the red-clay slope increased. Compared to the results of uncoupled analysis (Fig. 6), the water table in Fig. 5 is lower. However, after a span of time of 10 days, the water content of the red-clay reached steady state conditions again, and the difference between coupled analysis and uncoupled analysis vanished.

Figure 7 indicates that the pore-water pressures of the seven monitoring points changed significantly during the period of every rainfall-duration. Coupled and uncoupled calculation results are also presented in this chart. The differences of pore-water pressures among each monitoring points decrease with the duration of rainfall. For example, the difference in the pore water pressure was approximately $200 \mathrm{kPa}$ before the rainwater infiltrated into the slope, and it decreased to less than $60 \mathrm{kPa}$ at the end of 5 days of rainfall. Seven monitoring points are distributed at different locations, so the response of pore-water pressure of each point is not the same. The changes at points $\mathrm{T} 1, \mathrm{~T} 2$, and T3 are more remarkable than the others. At those locations, the matric suctions losses are $180 \mathrm{kPa}$, $140 \mathrm{kPa}$, and $120 \mathrm{kPa}$, respectively, after 5 days of rainfall infiltration. Although the matric suction change at other monitoring points appears to be large, the ranges are smaller than those at points $\mathrm{T} 1, \mathrm{~T} 2$, and $\mathrm{T} 3$.

Point T2 is at the crest of the slope. Figure 7 shows that the pore water pressure decreased by about 80,180 , 160,170 , and $190 \mathrm{kPa}$ at the end of 1 day, 2 days, 3 days, 4 days and 5 days of rainfall duration, respectively. The

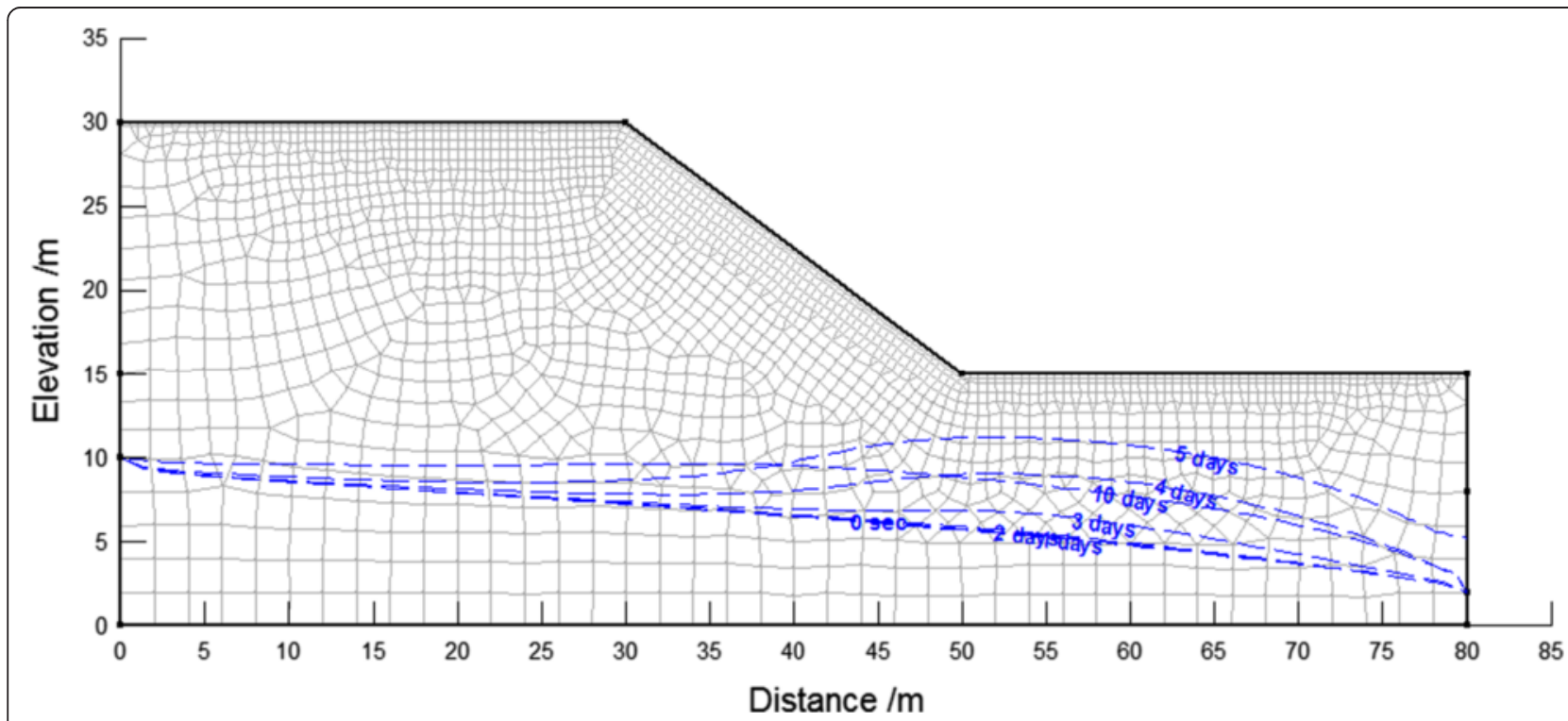

Fig. 5 Wetting front location for rainfall duration of 5 days (Coupled Analysis) 


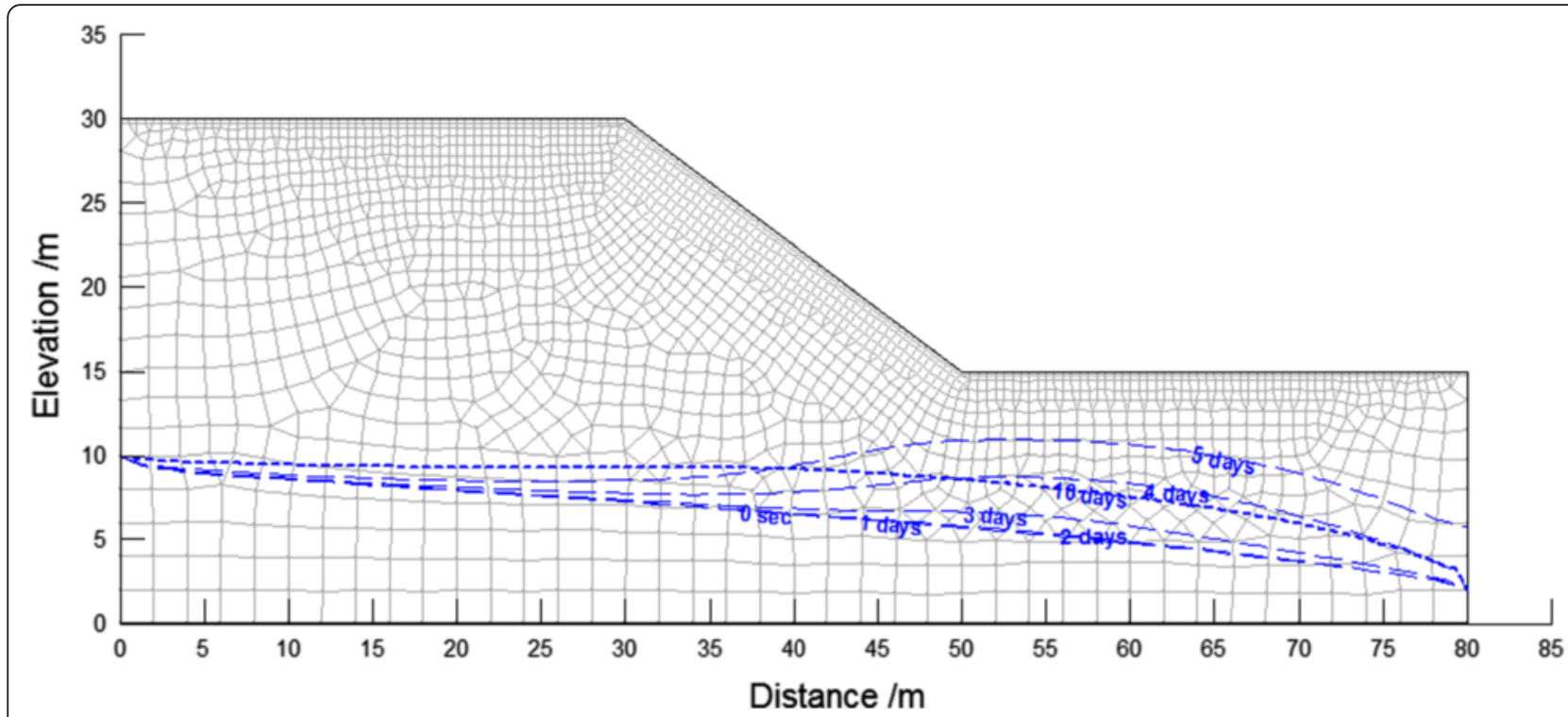

Fig. 6 Wetting front location for rainfall duration of 5 days (Uncoupled Seepage - only analysis)
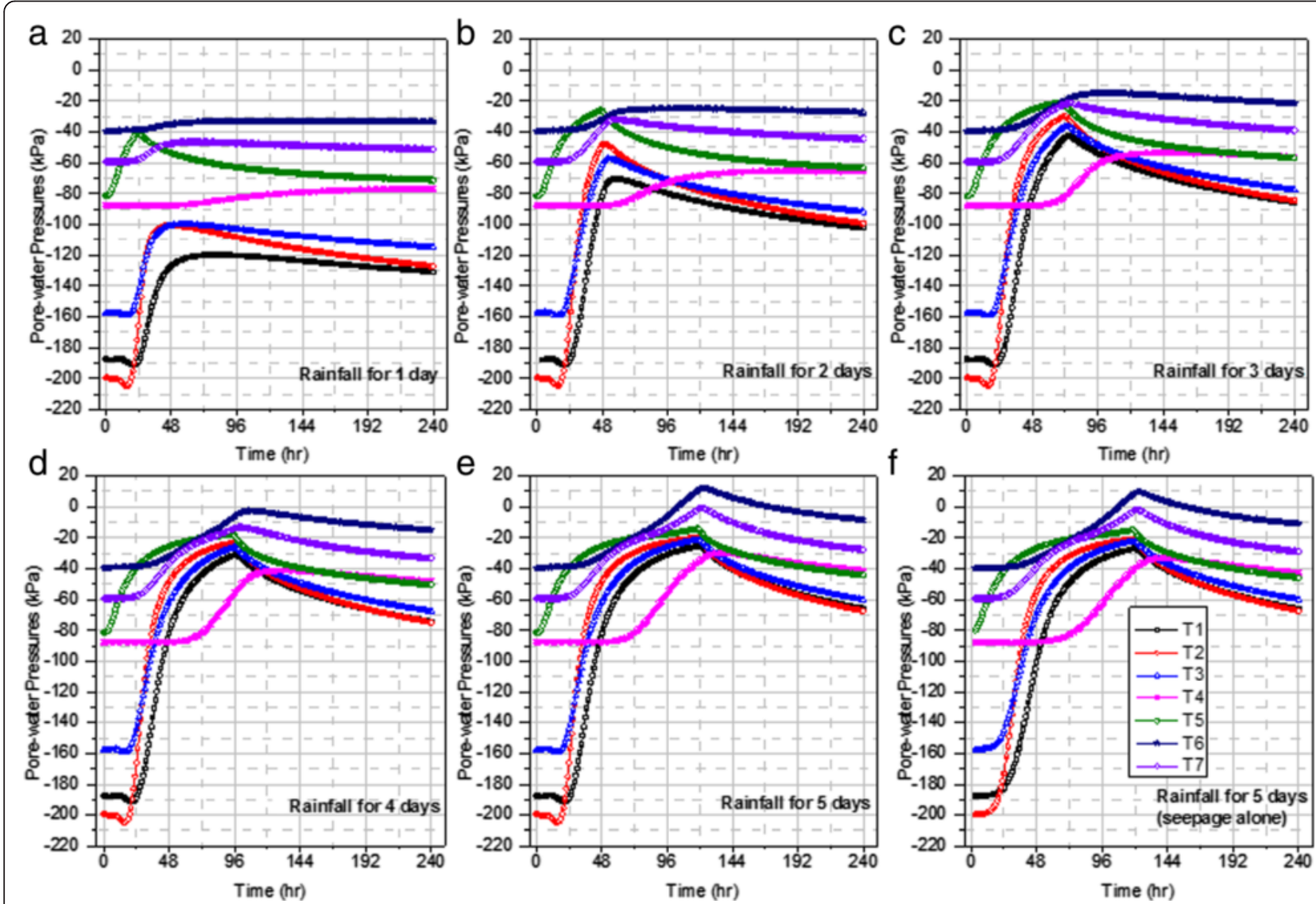

Fig. 7 Pore water pressure calculated at the monitoring points, versus time, for various rainfall durations of (a) 1 day, (b) 2 days, (c) 3 days, (d) 4 days, (e) 5 days and (f) 5 days for seepage only 

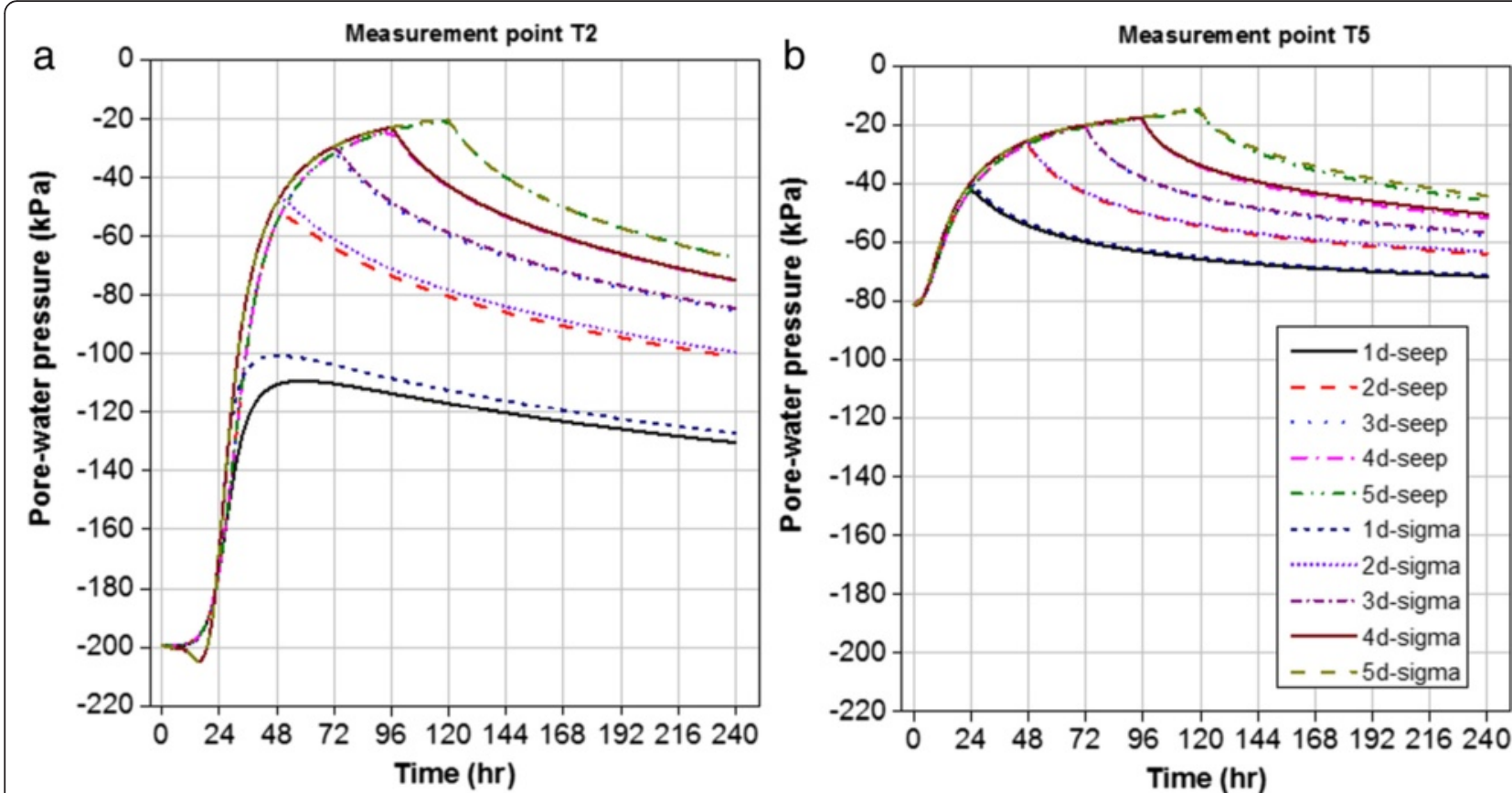

Fig. 8 Pore water pressure of coupled and uncoupled analysis, versus calculated time, for measure points: (a) T2 and (b) T5

initial pore-water pressure is smaller at the toe of the slope, but the rate of decrease in the pore pressures is the same as at the crest node. As the rainwater infiltrated into the slope during the rainfall process, the water table continuously increases as well. The monitoring data shows that red-clay at point $\mathrm{T} 6$ became saturated when the rainfall duration exceeded 4 days at which point the matrix suction disappeared and porewater pressure changed into a positive value.

The change of pore water pressure appears to be the obvious hysteresis phenomenon when compared to the rainfall duration. Point $\mathrm{T} 4$ is set deeper than the other points, Fig. 7 shows the pore-water pressure has no significant change in the period of the first 3 days, after which it appears to be decreasing. The results indicate that rainfall infiltration is a slow process to some extent, the pore-water pressure changes of the soil in different locations appear to occur in different hysteresis. The decreasing tendency continues after the rainfall-duration. The infiltration process did not stop even at the end of rainfall. Rainwater infiltrates from higher water content zones to lower water content zones and the water table appears to be at higher location. This phenomenon decreased the strength of the red-clay and reduced the stability of the slope.

The pore-water pressures changes at point $\mathrm{T} 2$ and $\mathrm{T} 5$ are the most remarkable. Figure 8 shows the results of the change in pore water pressure for the coupled and

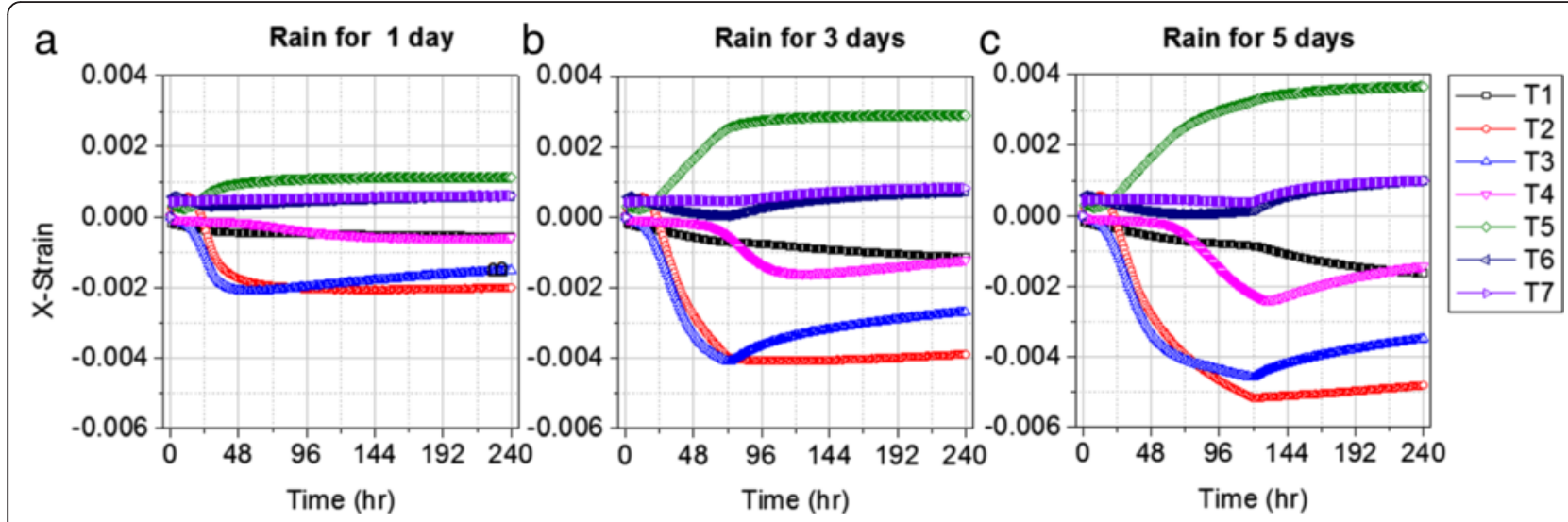

Fig. 9 Strain in X-direction (X-Strain) of monitoring points versus calculated time for rainfall durations: a 1 day, b 3 days, and c 5 days 

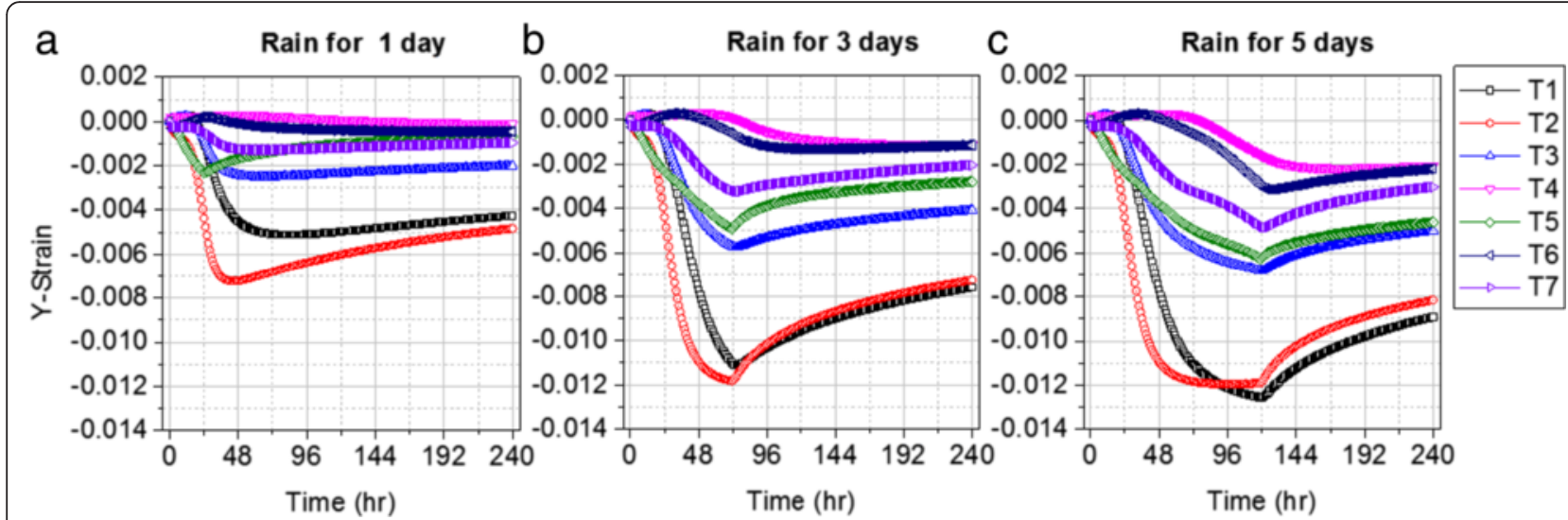

Fig. 10 Strain in Y-direction (Y-Strain) of monitoring points versus calculated time for rainfall durations: a 1 day, $\mathbf{b} 3$ days, and c 5 days

uncoupled analyses. Point T2 is at the crest of the slope where the pore-water pressure increased with time in the beginning of the rainfall infiltration process, then decreased. The pore-water pressures is larger until the end of the rainfall duration under the coupled calculation. Point T5 is at the toe of the slope. At this point, the results have no significant dissimilarity between coupled and uncoupled calculation. The difference between coupled and uncoupled analyses is whether the effect of the deformation on seepage process was considered or not. Therefore, the above results indicate that the displacement at the crest is larger than at the toe of the slope. Similar results were obtained for stress-strain and deformation analysis, which will be presented later in this paper.

\section{Response mechanism of strain distribution}

The matric suction exhibited different degrees of attenuation when compared to seepage during the rainwater infiltration process. Thus, the shear strength of red-clay decreased with time, and the unit weight of the red-clay also varied as the rainwater infiltrated into it. Hence, the horizontal strain (X-strain), the vertical strain (Y-strain), and the shear strain (XYshear strain) changed significantly at all monitoring points as presented in Figs. 9, 10, and 11, respectively. As presented in these figures, $\mathrm{X}$-strain increased at the points T2, T3 and T5 with an increase in rainfall duration, with tensile strain up to $4 \%$ at the points T2 and T3, and compressive strain at the toe up to $2 \%$. The changes of vertical normal strain at point $\mathrm{T} 1$ and $\mathrm{T} 2$ are significantly larger than at other points. In another words, vertical normal strain at the toe is remarkably larger than at the other zones. The analysis results show that all the Y-strains are compressive, while at some zones $\mathrm{X}$-strain appeared to be in tension. The distribution of XY-shear strain predicts the failure mode of slope; Fig. 11 shows that the values of XY-shear strain decreased, in sequence, at T3, T2, T5, T4, T6, T1, and T7 locations. This shows that the failures of the crest of slope would occur sooner than at the toe zones. The above figures also indicate that all changes of strain at the monitoring points show the consistency with the hysteresis quality of pore-water pressures with the XY-shear strain being most obvious in this regard.

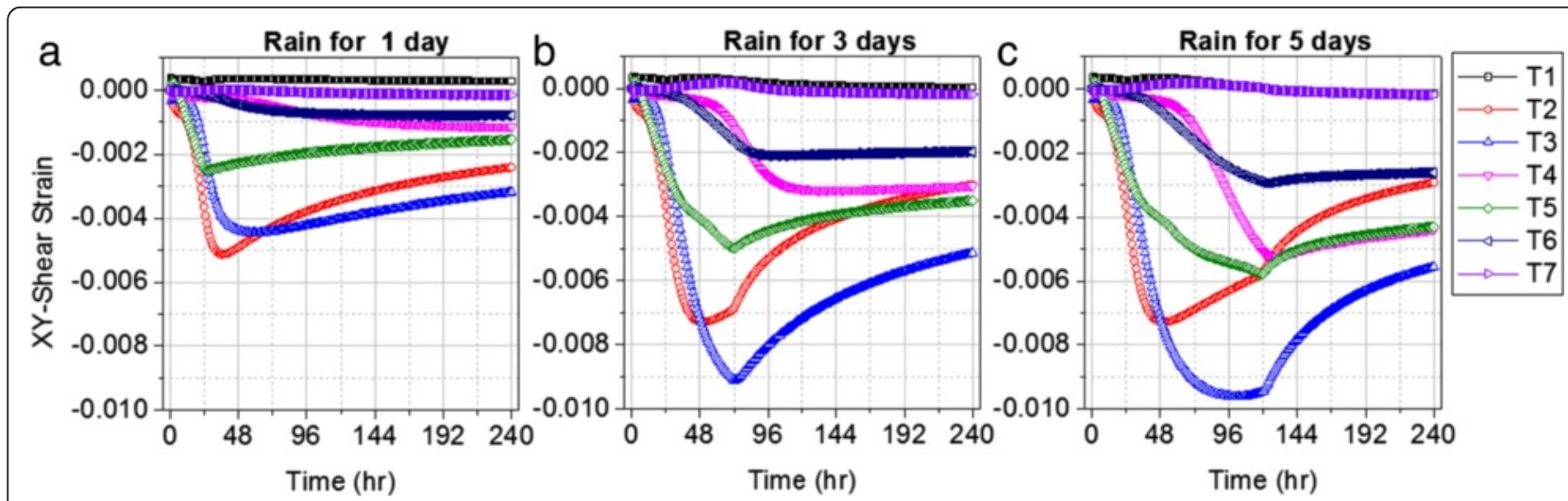

Fig. 11 Strain in XY direction (XY-Shear Strain) of monitoring points versus calculated time for rainfall durations: a 1 day, b 3 days, and c 5 days 


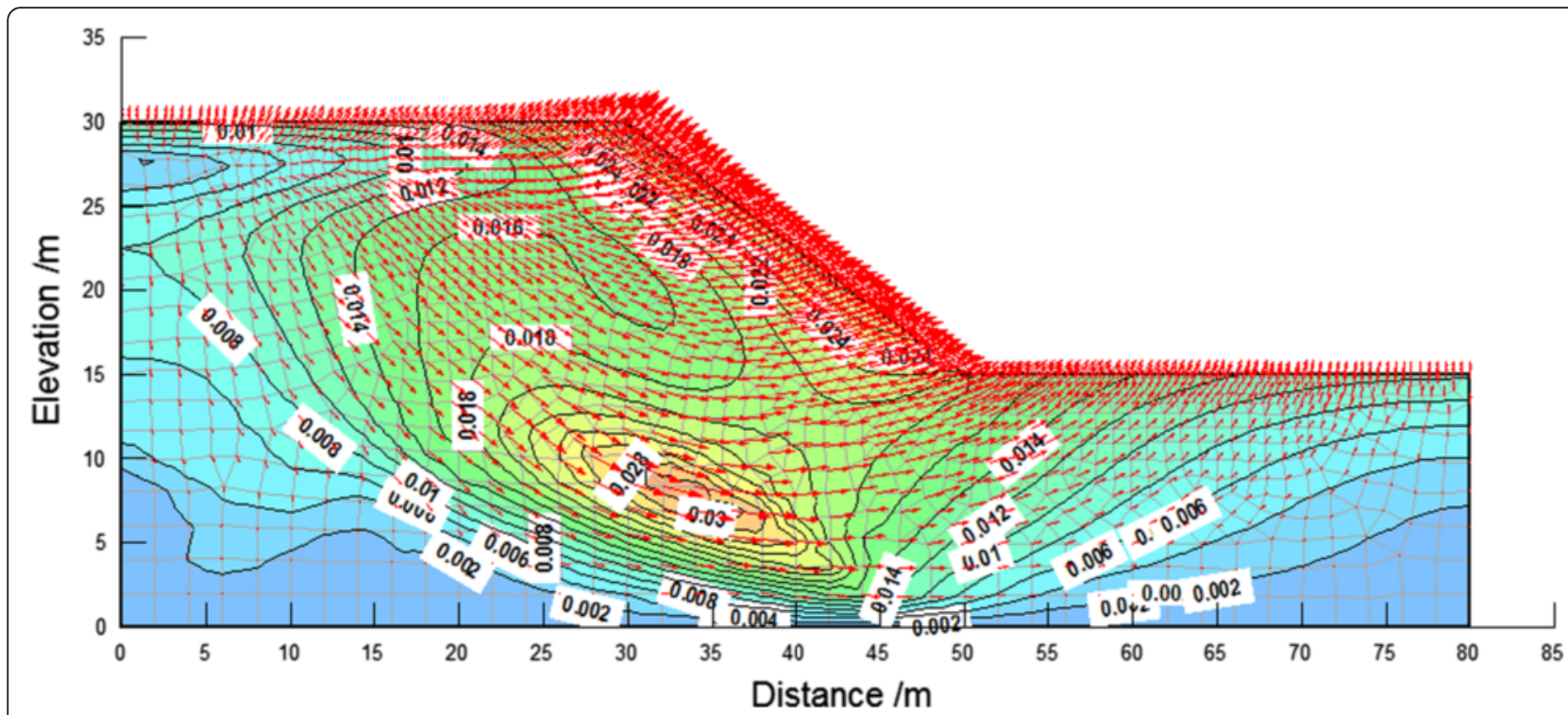

Fig. 12 The displacement of the mesh form at the 29th hour for the condition of rain for 1 day (the deformation scale is set to 22 times the scale for the distance)

\section{Deformation regularity}

During the earlier period of rainfall, the rainwater infiltrating into the slope does not reach the water table and the deformation of the red-clay appears to be in compression due to the added weight of rainwater. Following the prolonged rainfall duration, the rainwater percolated to the deeper locations, which increased the depth of perched water table with rainfall duration. The decrease in total deformation at these periods proves that the uplift force is larger than the weight added by rainwater infiltration in these periods (Figs. 12, and 13). Figure 14 shows XY-Displacement of the monitoring points versus rainfall times for rainfall durations of 1 day, 3 days, and 5 days. The quantitative calculation results indicate that XY-Displacement at points $\mathrm{T} 2$ and $\mathrm{T} 5$ are always larger than at other points. The changes of displacement at all points were spatially varying, affected by both the location of the water table and the distribution of porewater pressures. With regards to the hysteresis quality of displacement change, points $\mathrm{T} 1$ and $\mathrm{T} 6$ are more significant than any other points. Displacement at these two points increased faster during the rainfall infiltration

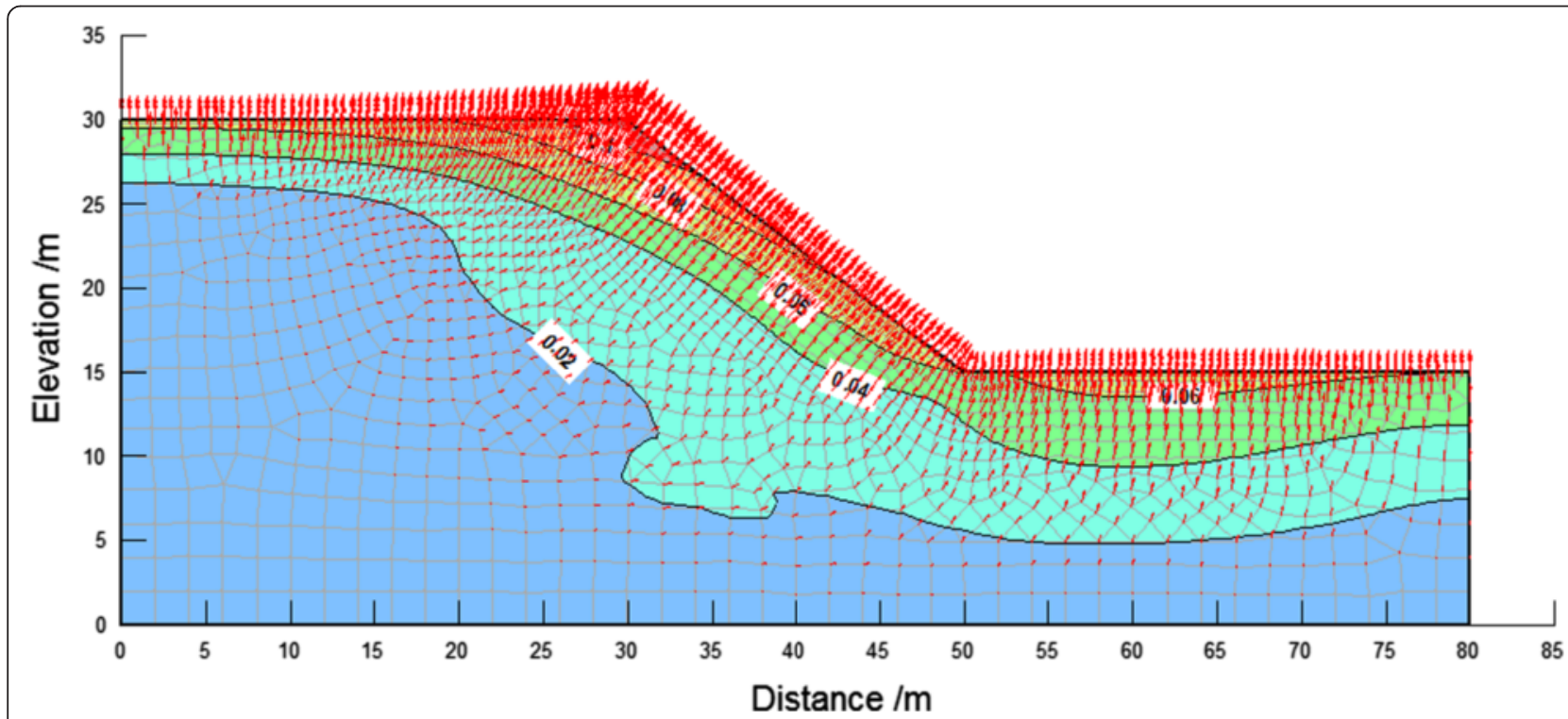

Fig. 13 The displacement of the mesh form at the 124th hour of rainfall for 5 days (the deformation scale is set to 22 times the scale for the distance) 

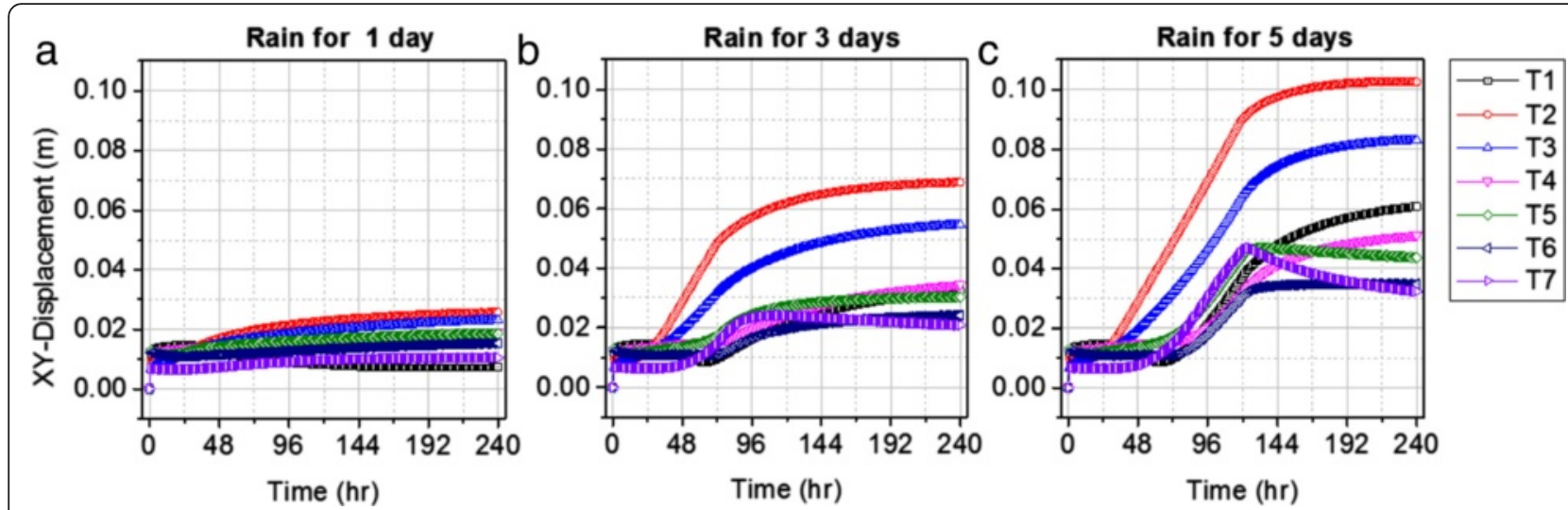

Fig. $14 \mathrm{XY}$-Displacement of the monitoring points versus calculated times for rainfall duration: a 1 day, b 3 days, and c 5 days

process. They exhibited the smallest displacement at the end of one day rainfall-duration, but up to almost the same value as at point T2. In general, the slope surface swelled in a non-uniform manner. Greatest amounts of swelling were observed at the head of the slope. According to the basic laws of physics, the stability of this slope will increase as a consequence of this phenomena.

The change of factor of safety during the rainfall-duration Figure 15 shows that the factor of safety (FoS) of the slope decreased with increases in the duration of rainfall. The FoS at the end of rainfall of durations 1 day, 2 days, 3 days, 4 days and 5 days decreased by $3.66 \%, 1.68 \%, 4.43 \%$, $7.82 \%$, and $4.54 \%$, respectively, with the cumulative reduction up to $10.62 \%$ in the coupled analysis. Similarly, in the uncouple analysis, the FoS decreased by $0.98 \%, 1.80 \%$, $1.20 \%, 2.30 \%$, and $4.33 \%$, respectively, with the cumulative reduction up to13.26\%. Looking into the situation as a whole, although there is no significant difference in the FoS reduction rate between the two calculation modes, the FoS from the coupled analysis was $2.58 \%$ higher than the FoS from the uncoupled analysis. The difference in FoS is due to the fact that void ratio in the red-clay changed significantly during the rainfall infiltration, which is mainly due to the deformation of the slope and the non-uniform swelling nature of the slope as a result of rainfall infiltration.

Compared to the time at the end of rainfall event, the exact time for minimum FoS $\left(\mathrm{F}_{\min }\right)$ also exhibited hysteretic characteristics. This result agrees with previous research findings. The hysteretic qualities among different rainfall durations were not the same. In the coupled calculation mode, the delayed times were: $3 \mathrm{~h}, 6 \mathrm{~h}, 5 \mathrm{~h}$, $8 \mathrm{~h}$, and $21 \mathrm{~h}$, respectively, for the five rainfall durations whereas in uncoupled calculation mode the delayed times were: $2 \mathrm{~h}, 3 \mathrm{~h}, 20 \mathrm{~h}, 1 \mathrm{~h}$, and $4 \mathrm{~h}$, respectively. The results indicate that seepage in the slope is controlled by the deformation. After FoS reached to the minimum value, rainwater infiltration process continued and the moisture of red-clay near the slope top decreased with time, gradually increasing the matric suction. Due to this
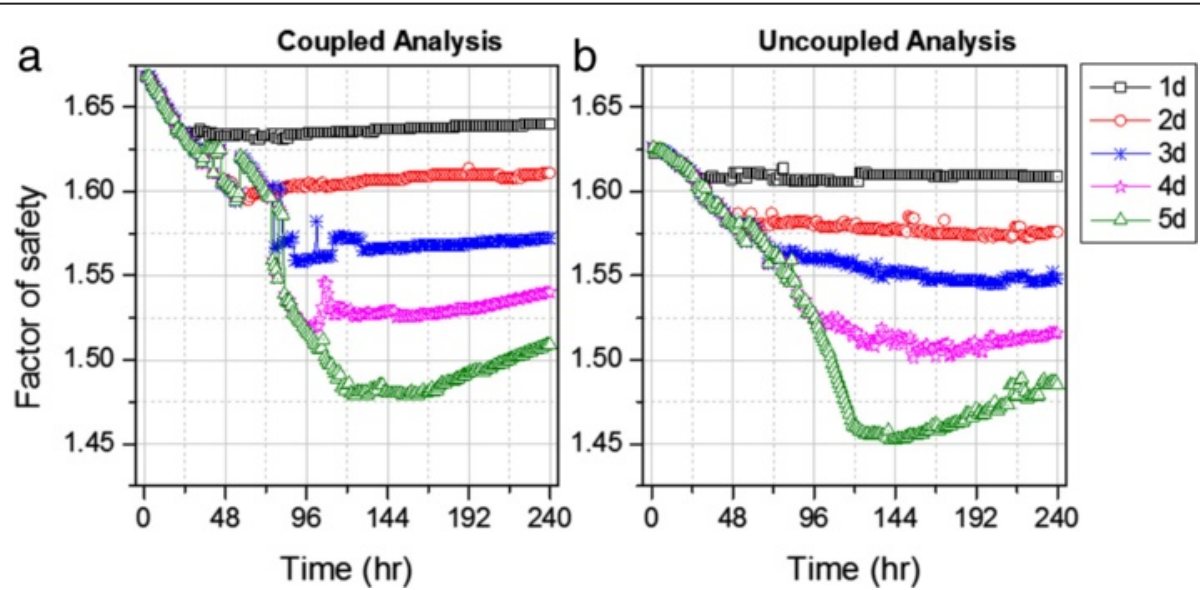

Fig. 15 Factor of safety from (a) coupled and (b) uncoupled analysis versus calculation times for various rainfall conditions: 1 day, 2 days, 3 days, 4 days, and 5 days 
fact, the soil deformation reduced gradually, slightly increasing the FoS during the later calculation period.

Figure 15 shows that under the coupled analysis mode, the FoS increased slightly during the calculation steps, which can be attributed to the effect between deformation and seepage force in the slope body. Rainwater would reach to the potential sliding surface of the slope, increasing the deformation and nodes displacement as well as void ratio and matric suction due to a temporary decrease in the moisture content. As rainwater continually infiltrates into the red-clay voids, the matric suction reduces due to the increase in the moisture content, and eventually, reduces the shear strength of soil and the stability of the slope. Additionally, shear strength and slope stability is controlled not only by the pore-water pressures, but also by the underground water table. It is a complex process, which cannot simply be explained through linear or spline relationships. Therefore, the FoS values increased slightly after certain time periods.

\section{Conclusions}

Based on the analytical and numerical investigations presented in this paper, the following conclusions can be made:

Rainfall infiltration process affected the shear strength of the red-clay slope. During the rainfall, pore-water pressures increased due to the dissipation of matric suctions and a rise in the elevation of the water table. Pore-water pressures increased with the increase in the rainfall duration. The longer the rainfall duration, the larger the pore-water pressure and higher the rate of pore water pressure increase. The monitoring data at seven points indicate that the change of pore-water pressures at the crest zone is larger than at the toe of slope.

Due to the change in pore-water pressure and unit weight as a result of the added rainwater infiltrated into the soil, the strain and deformation of red-clay changed significantly. At the crest of the slope, tension strains are seen in the horizontal direction and compression strains in the vertical direction. However, at the toe of the slope, all of the strains were in compression. After short duration rainfalls, compressive settlement of the slope surface is observed. However, in long duration rainfalls, the slope surface exhibited non-uniform swelling with the largest magnitude of swelling at the head of the slope.

The factor of safety decreased sharply during the period of rainfall. The exact time for minimum value of FoS was delayed after the end of rainfall events. The hysteresic phenomenon for the calculated FoS is similar to that seen in the pore water pressure. The FoS increased slightly during the calculation steps under the coupled calculation analysis, mainly due to the fact the deformation and seepage influenced each other. Both processes jointly controlled the stability of the slope.
These results are beneficial to understand the initiation of deformation process in red-clays during different durations of rainfall and be prepared for landslide mitigation during rainy season.

\section{Competing interests \\ The authors declare that they have no competing interests.}

\section{Authors' contributions}

$\mathrm{KX}$ conceived the study and worked with $\mathrm{YH}$ to conduct the numerical simulations and analyzed the data obtained. BT, BA and KX helped to interpret the results and prepare the first draft of the manuscript. All authors read and approved the final manuscript.

\section{Acknowledgements}

This study was funded by National Natural Science Foundation of China (41462011) and Natural Science Foundation of Jiangxi Province, China (20122BAB216002). This study was completed during the first author's stay at California State University, Fullerton as a visiting scholar, which was funded

by China Scholarship Council and Education Department of Jiangxi Province.

\section{Author details}

${ }^{1}$ Civil \& Architecture Engineering Department, State Key Laboratory Breeding Base of Nuclear Resources and Environment, East China University of Technology, 418 Guanglan Rd, Nanchang 330013, Jiangxi, China. ${ }^{2}$ Civil \& Environmental Engineering Department, California State University, $800 \mathrm{~N}$ State College Blvd, E-318, 92831 Fullerton, CA, USA. ${ }^{3}$ Civil \& Environmental Engineering Department, California State University, 800 N State College Blvd, E-419, 92831 Fullerton, CA, USA.

Received: 19 January 2016 Accepted: 24 May 2016

Published online: 01 June 2016

\section{References}

Brooks, S.M., and K.S. Richards. 1994. The significance of rainstorm variations to shallow translational hillslope failure. Earth Surface Processes and Landforms 19(1): 85-94.

Dhakal, A.S., and R.C. Sidle. 2004. Distributed simulations of landslides for different rainfall conditions. Hydrological Processes 18(4): 757-776.

Fredlund, D.G., and H. Rahardjo. 1993. Soil mechanics for unsaturated soils. New York: John Wiley \& Sons

Fredlund, D.F., and A. Xing. 1994. Equations for the soil-water characteristic curve. Canadian Geotechnical Journal 31: 521-532.

GEO-SLOPE International, Ltd. 2013. Stress-Deformation Modeling with SIGMAW. Calgary: GEO-SLOPE International, Ltd.

GEO-SLOPE International, Ltd. 2014a. Seepage Modeling with SEEP/W. Calgary: GEO-SLOPE International, Ltd.

GEO-SLOPE International, Ltd. 2014b. Stability Modeling with SLOPEN. Calgary: GEO-SLOPE International Ltd.

Keefer, D.K., R.C. Wilson, R.K. Mark, E.E. Brabb, W.M. Brown III, S.D. Ellen, E.L. Harp, G.F. Wieczorek, C.S. Alger, and R.S. Zatkin. 1987. Real-time landslide warning during heavy rainfall. Science 238(4829): 921-925.

Liu, X., L. Zou, and B. Song. 2012. Research on Unsaturated Hydro-mechanical Coupling Characteristic of a Slope considering Rainfall Infiltration and Stability Assessment. Disaster Advances 5(4): 1615-1622.

Lumb PB (1962) Effects of rain storms on slope stability. Symposium on Hong Kong Soils 73-87. Hong Kong: Local Property \& Printing Company, Limited.

Mukhlisin, M., and M.R. Taha. 2012. Numerical model of antecedent rainfall effect on slope stability at a hillslope of weathered granitic soil formation. Journal of the Geological Society of India 79(5): 525-531.

$\mathrm{Ng}, \mathrm{C}$. and Q. Shi. 1998. Influence of rainfall intensity and duration on slope stability in unsaturated soils. Quarterly Journal of Engineering Geology 31(2): 105-113.

Rahardjo, H., X.W. Li, D.G. Toll, and E.C. Leong. 2001. The effect of antecedent rainfall on slope stability. Geotechnical \& Geological Engineering 19(3-4): 371-399.

Rahimi, A., H. Rahardjo, and E. Leong. 2010. Effect of Antecedent Rainfall Patterns on Rainfall-Induced Slope Failure. Journal of Geotechnical and Geoenvironmental Engineering 137(5): 483-491. 
Song, X., W. Xu, J. Shao, and R. Xu. 2002. Stability analysis of unsaturated soil slope under atomized rain. Journal of Hohai University Natural Sciences 30(56): 16-20 (In Chinese)

Tiwari, B., and S. Upadhyaya. 2014. Influence of Antecedent Rainfall on Stability of Slopes. American Society of Civil Engineers Proceedings of GeoCongress 2014: 3243-3251

Tsai, T. 2008. The influence of rainstorm pattern on shallow landslide. Environmental Geology 53(7): 1563-1569.

Tsai, T., and J. Wang. 2011. Examination of influences of rainfall patterns on shallow landslides due to dissipation of matric suction. Environmental Earth Sciences 63(1): 65-75.

Wang, J., and B. Liang. 2010. Affection of Rainfall Factor to Seepage and Stability of Loess Slope. Journal of Water Resources and Water Engineering 21 (1): 42-45.

Xue, K., Y. Hu, Z. Yang, M. Hu, and L. Gu. 2012. Identification model of extreme rainfall events induced mountain road geological disasters. Journal of east china institute of technology 28(3): 263-269 (in Chinese).

Zhang, L., Y. Zheng, S. Zhao, and W. Shi. 2003. The feasibility study of strength-reduction method with FEM for calculating safety factors of soil slope stability. Shuili Xue Bao 45(1): 21-27 (in Chinese).

\section{Submit your manuscript to a SpringerOpen ${ }^{\odot}$ journal and benefit from:}

- Convenient online submission

- Rigorous peer review

- Immediate publication on acceptance

- Open access: articles freely available online

- High visibility within the field

- Retaining the copyright to your article

Submit your next manuscript at $\boldsymbol{s p r i n g e r o p e n . c o m ~}$ 